\title{
Communal Sharing and the Provision of Low-Volume High-Cost Health Services: Results of a Survey
}

\author{
Jeff Richardson $^{1} \cdot$ Angelo Iezzi $^{1} \cdot$ Gang Chen $^{1} \cdot$ Aimee Maxwell $^{1}$
}

Published online: 4 November 2016

(c) The Author(s) 2016. This article is published with open access at Springerlink.com

\begin{abstract}
Introduction This paper suggests and tests a reason why the public might support the funding of services for rare diseases (SRDs) when the services are effective but not cost effective, i.e. when more health could be produced by allocating funds to other services. It is postulated that the fairness of funding a service is influenced by a comparison of the average patient benefit with the average cost to those who share the cost.

Methods Survey respondents were asked to allocate a budget between cost-effective services that had a small effect upon a large number of relatively well patients and SRDs that benefited a small number of severely ill patients but were not cost effective because of their high cost.

Results Part of the budget was always allocated to the SRDs. The budget share rose with the number sharing the cost.

Discussion Sharing per se appears to characterise preferences. This has been obscured in studies that focus upon cost per patient rather than cost per person sharing the cost.
\end{abstract}

Electronic supplementary material The online version of this article (doi:10.1007/s41669-016-0002-3) contains supplementary material, which is available to authorized users.

Jeff Richardson

Jeffrey.richardson@monash.edu

1 Centre for Health Economics, Level 2, 15 Innovation Walk, Monash Business School, Monash University, Clayton, VIC 3800, Australia

\section{Key Points for Decision Makers}

Public support is found for some funding of effective but cost-ineffective services for rare diseases (SRDs).

Funding SRDs is feasible because of their low total and per person cost.

Funding SRDs subject to a budget constraint redistributes resources from low- to high-severity conditions.

\section{Introduction}

The theory of economic evaluation commonly commences with the assumption that, all else equal, the social objective of the health sector is the maximisation of quality-adjusted life-years (QALYs). With a fixed budget, this is achieved by selecting services with the lowest cost per QALY. However, it is widely recognised that the simple 'QALY model' may omit important considerations, with a recent review of the field concluding that "the recognition that CEA [cost-effectiveness analyses] cannot readily accommodate every concern ... has led nearly every group that recommends the use of CEA ... also to recommend that decisions ... should take into account important factors that are not embedded in the analysis" [1]. Similarly, Drummond et al. [2] noted that "economic evaluation does not usually incorporate the importance of the distribution of costs and consequences ... which may be an important factor in assessing the social desirability of a service or program”. 
In response to these concerns, there has been a growing literature that focuses upon the variables omitted from the 'QALY model'. A number of reviews of this literature now exist [3-7]. Variables identified as important include, inter alia, the severity of untreated illness, patient age and a lifetime 'fair innings'. More recently, the significance of 'rarity' has become a controversial issue because of the rapid expansion of services for 'orphan disorders', which are defined in the USA and EU legislation as disorders with a prevalence of fewer than 200,000 individuals (USA) and fewer than 5 per 10,000 of the population (EU) [8]. A number of countries have adopted policies to support market access to these services [9], and it has been argued that the current evaluation framework should accommodate the preferences revealed by these policies [9-14]. However, the majority of writers have argued that rarity per se should not be a relevant consideration: health is maximised by the selection of cost-effective services irrespective of their rarity [15-21]. Survey evidence [15, 17, 22-24] indicates no preference for services for rare diseases (SRDs) when the choice is between 'rare and common diseases' [16].

Nevertheless, a limited number of studies have observed a public preference for allocating some part of a limited budget to services that are efficacious but not 'cost effective' because of their high cost [25-30]. In one of these studies, members of focus groups explained their choice in terms of the preservation of hope [29], an explanation also suggested by Nord et al. [25].

The present paper adds to this literature and suggests and tests an additional reason why the public might support the funding of SRDs. The study hypothesis is that people's evaluation of fairness is influenced by a comparison of the benefit to a patient with the average cost to a person who shares the cost. With small patient numbers, SRDs imply a small total cost and therefore a small average cost to those bearing the cost. If this is sufficiently small relative to the patient's benefit, provision of the SRD may be seen as equitable. The key test of this 'sharing' hypothesis, presented below, is that, as the numbers sharing the cost rise and the average effect upon those bearing the cost falls, support for the funding of SRDs will rise.

An analogy to the hypothesised reasoning occurs when a sailor is lost at sea and the cost of a successful rescue is low, say $\$ 5.00$ per person. It is likely the majority would vote for the payment. If they were advised that the rescue required $\$ 5.00$ from 1 million people and that the rescue was not cost effective, the study hypothesis suggests that people would still vote for a compulsory $\$ 5.00$ levy. The choice between a person's life and (a possibly involuntary) $\$ 5.00$ per person levy may appear ethically unambiguous.

Two surveys are reported below that test the 'sharing' hypothesis and three subsidiary hypotheses. These are that as the price of the high-cost service rises (1) funds per service will fall: 'normal substitution'; (2) the budget share will fall: 'weak sharing'; and (3) the budget share will rise: 'strong sharing'.

Section 2 describes the surveys, and results are presented in Sect. 3. The discussion in Sect. 4 includes, inter alia, a consideration of the arguments that funding SRDs would be infeasible because of their large numbers and ethically unacceptable as it would reduce total health.

\section{Methods}

In sum, respondents to an Australian web-based survey were asked to divide a budget between a small group of patients with a high-cost illness (A) and a large number of patients with a low-cost illness (B). Treatments were divisible, and the quality of life of both groups of patients rose with the funds allocated to them. The difference in treatment costs ensured that expenditures upon illness B were always more cost effective. The symptoms of the two illnesses were identical and were evaluated separately to allow an estimate of the net QALY loss from expenditure upon illness $\mathrm{A}$. The number of patients $\mathrm{B}$, and the cost of illness A, were varied. The study hypotheses were tested by observation of the allocation of resources to illness A. Regression analyses were conducted to determine the importance of the variables that explained the budgetary allocation to illness $\mathrm{A}$.

\subsection{Surveys}

Two web-based surveys were administered by a talking avatar to members of the public who were enrolled with a panel company, CINT Pty Ltd. Participants were selected at random from their age-sex cohort until a predetermined quota was filled, which was calculated to obtain a representative profile of the age-sex composition of the Australian population. Both surveys were divided into three parts. First, questions were asked to familiarise respondents with relevant health states that were then evaluated on a visual analogue scale (VAS). The second and major part of the survey asked respondents to divide the available budget between the small number of high-cost patients (A) and the large number of low-cost patients (B) as the relative cost of treatment, the number of low-cost patients and the total budget varied. In the final part, the agreement/disagreement questions were asked to gain insight into people's reasons for their previous answers.

\subsubsection{Part 1}

Respondents were asked to rank four health states relating to walking and self-care. Using terminology from the 
descriptive system of the EuroQoL Five-Dimensions FiveLevels (EQ-5D-5L), levels of disability were described as 'slight', 'moderate', 'severe' and 'unable to walk and selfcare'. An explanation of a VAS was provided (reproduced in Appendix 1 in the Electronic Supplementary Material [ESM]), and participants were asked to rate the four health states using the VAS. Scores were converted into time trade-off (TTO) utilities using a transformation described in the ESM (Appendix 2).

\subsubsection{Part 2}

The second part of the survey was introduced by the avatar as follows:

Suppose you live in a small town of 1000 people ... next year, two illnesses will occur ... illness A and illness B. Both illnesses have the same symptoms which are problems with mobility and self-care. Five people will get illness $\mathrm{A}$ and 100 people will get illness B. Anyone in the town ... may get one of the illnesses. You, personally, could be one of these people.

... without treatment patients will die. With some treatment patients will be saved from death but left with problems with walking and self-care such as dressing, washing and toileting. The more treatment the patient receives the more their health will be improved until the illness is cured. The effect of the treatment ... lasts 10 years after which it will have to be repeated.

Because the causes of the illnesses are very different, the cost of treatment for the two illnesses is very different ... the government has allocated a fixed budget ... which is not enough to provide a full cure for everyone. Extra private spending is not possible and no other services will cure the illness. The questions are about how you think the government should distribute its money.

Respondents were then presented with a series of figures that summarised the parameters of the choices they were to make (see Box 1). The descriptions of health states in these figures were aligned with the percentage of cost coverage, the numerical value of which equalled 100 times the utility of the health states. These were obtained from an earlier study that had used the same scale and descriptors [31]. Therefore, in selecting a level of cost coverage, respondents were selecting the health state utility that would be experienced by patients if they contracted the illness.

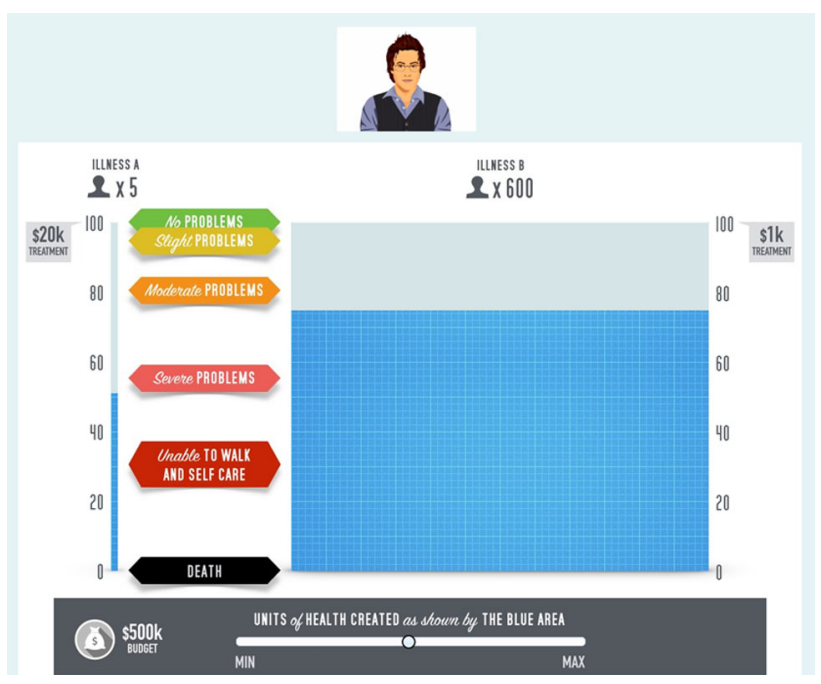

Box 1 Visual aid for budget allocation

The avatar continued:

Using the slider you can choose how to divide the money between the two illnesses and therefore how much health to create for each group of patients ... which is represented by the size of the blue areas. Moving the handle all the way to the right creates the maximum total amount of health as shown by the large blue area. This is because illness B is cheaper to cure so you can buy the most units of health if you spend all of the funds on illness B. But if you do this the five patients with illness A will get nothing and they all die.

Moving the handle all the way to the left creates the minimum total amount of health... This is because illness A is more expensive to cure so you're buying less units of health when you spend on illness A. When you do this (survey 1 continued) 100 patients with illness B get nothing and they all die. (Survey 2 continued) The 600 patients with illness B get less health.

The budget, the cost of cure and the number of patients $B$ in the two surveys were varied as shown in Table 1. The number of patients A remained unchanged at five; patients $\mathrm{B}$ varied from 100 to 600 . The cost of illness B was unchanged at $\$ 1000$; for illness $A$ it varied from $\$ 2000$ to $\$ 20,000$. The budget changed with the number of patients. To mitigate order effects, the scenarios were administered in reverse order in the two surveys. The visual representation of the health of patients B expanded and contracted to scale with the number of patients. Possible combinations of health were calculated by an algorithm that altered the (blue) visual display of the total health of both groups as the respondent moved the slider. 
Table 1 Survey parameters

\begin{tabular}{|c|c|c|c|c|c|c|c|}
\hline \multicolumn{4}{|c|}{ Both surveys } & \multirow{2}{*}{\multicolumn{2}{|c|}{ Survey 1}} & \multirow{2}{*}{\multicolumn{2}{|c|}{ Survey 2}} \\
\hline \multicolumn{2}{|c|}{ Number of patients } & \multicolumn{2}{|l|}{ Cost of cure } & & & & \\
\hline Group A & Group B & A $\$ 000$ & B $\$ 000$ & Order delivered & Budget (\$000) & Order & Budget $(\$ 000)$ \\
\hline 5 & 100 & $20,15,10,5,2$ & 1.00 & 1 & 100 & 3 & 100 \\
\hline 5 & 300 & $20,15,10,5,2$ & 1.00 & 2 & 300 & 2 & 250 \\
\hline 5 & 600 & $20,15,10,5,2$ & 1.00 & 3 & 600 & 1 & 500 \\
\hline
\end{tabular}

After several introductory tasks described in the ESM (Appendix 6), respondents were asked to allocate the budget in each scenario. However, before an answer was accepted, respondents were asked to respond to the following statement about their choice:

Notice that you are reducing total health so that health can be shared. Please confirm this is what you think should be done. Are you sure you want the XXX patients with illness $\mathrm{B}$ to have only $\mathrm{XX} \%$ of full health so that the 5 patients with illness A can live and have $\mathrm{X} \%$ of full health?

The figures $\mathrm{XXX}, \mathrm{XX}$ and $\mathrm{X}$ were inserted by the algorithm. The allocation to $\mathrm{A}$, foregone expenditure on $\mathrm{B}$ and therefore foregone QALYs were calculated for each of the scenarios in Table 1.

Regression analyses were used to investigate factors associated with the decision of budget allocation. The dependent variable in each regression was the percent cover of the cost of illness A. Independent variables included the price of treating illness $A$, the number of patients with illness $\mathrm{B}$, the total budget to be allocated and respondents' demographic characteristics, including sex and a set of age dummies. The ordinary least squares (OLS) method was used. Considering that each respondent answered 15 questions, a fixed-effects (FE) estimator was further adopted. Cluster robust standard errors were reported. Regression analyses were conducted using Stata version 13.1 (StataCorp LP; College Station, TX, USA).

\subsubsection{Part 3}

Respondents were asked to use a Likert scale to rate the importance of six possible influences upon their budget allocations and to agree/disagree with three reasons for the provision/non-provision of high-cost services.

Two edit criteria were used to remove results that indicated a misunderstanding of questions or serious inconsistency. These are described in the ESM (Appendix 4), which also reports a comparison of key results estimated with both edited and unedited data.
The survey was approved by the Monash University Human Research Ethics Committee; approval ID: CF15/ 411-2015000201.

\section{Results}

A total of 702 respondents completed the questionnaire: 353 in survey 1 and 349 in survey 2 . Of these, $38 \%$ failed one of the two edit criteria, leaving the sample of 432 , comprising 221 in survey 1 and 211 in survey 2. From ESM Appendix 4, the percentage edited was lower in the age range 18-24 years but similar in other age-sex cohorts. The key result-variation in the allocation to patients $\mathrm{A}-$ did not vary significantly with the use of edited and unedited data. Demographic characteristics of the edited sample are reported in Table 2. The sample closely resembles the demographic structure of the Australian public, which is reported in the final row of the table.

VAS scores for the two sets of health states and the estimated TTO utilities are reported in Table 3. For the top two states-slight and moderate problems - the average VAS scores were 4 and 3 percentage points lower than those obtained in the earlier survey [31], which were incorporated in the figures. The lower health state utilities were identical to the earlier estimates.

The percentages of the full cost of care allocated to patients A and B in the two surveys are given in Table 4. In each scenario, there was a significant allocation of resources to services for illness A despite this lowering total health. Increasing the number of patients $B$, who shared the opportunity cost of services for $A$, increased the coverage of illness $\mathrm{A}$ in all but two cases. The exceptions occurred in survey 2 when there were 300 patients B and the cost of A was $\$ 2000$ and $\$ 5000$. The result may be explained by the reduction in the budget in survey 2 . However, an order effect may have been a contributory factor.

Results in Table 4 indicate that the order of presentation of questions had a small but significant effect. When there were 100 patients, identical questions were asked but in reverse order. When $\mathrm{P}_{\mathrm{A}}=\$ 2000$, survey 1 respondents 
Table 2 Demographics-percentages

\begin{tabular}{|c|c|c|c|c|c|c|c|c|c|c|c|}
\hline & \multicolumn{7}{|c|}{ Age groups, years } & \multicolumn{3}{|c|}{ Educational level } & \multirow{2}{*}{$\begin{array}{l}\text { Totals } \\
n\end{array}$} \\
\hline & $18-24$ & $25-34$ & $35-44$ & $45-54$ & $55-64$ & $\geq 65$ & Total & High school & Dip/Trade/TAFE & Uni & \\
\hline \multicolumn{12}{|l|}{ Survey 1} \\
\hline Male & 9.4 & 14.0 & 21.5 & 21.5 & 15.9 & 17.7 & 100 & 27.1 & 29.9 & 43.0 & 107 \\
\hline Female & 15.8 & 13.1 & 15.8 & 21.1 & 18.4 & 15.8 & 100 & 19.3 & 43.0 & 37.7 & 114 \\
\hline Total & 12.7 & 13.6 & 18.5 & 21.3 & 17.2 & 16.7 & 100 & 23.1 & 36.7 & 40.2 & 221 \\
\hline \multicolumn{12}{|l|}{ Survey 2} \\
\hline Male & 14.4 & 17.1 & 21.6 & 16.2 & 12.7 & 18.0 & 100 & 23.4 & 19.8 & 56.8 & 111 \\
\hline Female & 20.0 & 12.0 & 17.0 & 22.0 & 11.0 & 18.0 & 100 & 22.0 & 29.0 & 49.0 & 100 \\
\hline Total & 17.1 & 14.7 & 19.4 & 19.0 & 11.9 & 18.0 & 100 & 22.7 & 24.2 & 53.1 & 211 \\
\hline \multicolumn{12}{|l|}{ Total } \\
\hline Male & 11.9 & 15.6 & 21.6 & 18.8 & 14.2 & 17.9 & 100 & 25.2 & 24.8 & 50.0 & 218 \\
\hline Female & 17.8 & 12.6 & 16.4 & 21.5 & 14.9 & 16.8 & 100 & 20.5 & 36.5 & 43.0 & 214 \\
\hline Total & 14.8 & 14.1 & 19.0 & 20.1 & 14.6 & 17.4 & 100 & 22.9 & 30.6 & 46.5 & 432 \\
\hline \multicolumn{12}{|l|}{ Australia $^{a}$} \\
\hline Total & 11.0 & 19.3 & 18.2 & 17.5 & 15.0 & 19.0 & 100 & & & & \\
\hline
\end{tabular}

Data are presented as percentages

TAFE Technical and Further Education

${ }^{a}$ Source: Australian Bureau of Statistics [38]

Table 3 Visual analogue scale and estimated time trade-off utilities

\begin{tabular}{llllll}
\hline Health state & TTO mean $^{\mathrm{a}}$ & VAS mean $^{\mathrm{a}}$ & SD & Max & Min \\
\hline Slight problems with walking and self-care & 0.90 & 0.76 & 0.12 & 1.00 & 0.30 \\
Moderate problems with walking and self-care & 0.77 & 0.59 & 0.12 & 0.95 & 0.20 \\
Severe problems with walking and self-care & 0.61 & 0.44 & 0.12 & 0.96 & 0.10 \\
Unable to walk and self-care & 0.29 & 0.19 & 0.12 & 0.85 & 0.0 \\
\hline
\end{tabular}

ESM electronic supplementary material, $S D$ standard deviation, TTO time trade-off, VAS visual analogue scale

${ }^{\mathrm{a}}(1-\mathrm{TTO})=(1-\mathrm{VAS})^{1.62}$ Source: Appendix 2 in the ESM

b The 100-point results from the 100-point scale (Box 2, Appendix 2 in the ESM) were divided by 100

Table 4 Percent of full cost allocated to patients A, patients B

\begin{tabular}{|c|c|c|c|c|c|c|c|c|c|c|c|c|c|c|}
\hline \multirow[t]{3}{*}{ Survey } & \multirow{3}{*}{$\begin{array}{l}\text { Number of } \\
\text { patients B }\end{array}$} & \multirow{3}{*}{$\begin{array}{l}\text { Budget } \\
(\$ 000)\end{array}$} & \multicolumn{5}{|c|}{$\%$ of full cost given to $\mathrm{A}$} & \multirow{3}{*}{$\begin{array}{l}\text { Max- } \\
\text { Min }\end{array}$} & \multicolumn{5}{|c|}{$\%$ of full cost given to $\mathrm{B}$} & \multirow{3}{*}{$\begin{array}{l}\text { Max- } \\
\text { Min }\end{array}$} \\
\hline & & & \multicolumn{5}{|c|}{ Price A } & & \multicolumn{5}{|c|}{ Price A } & \\
\hline & & & 2000 & 5000 & 10,000 & 15,000 & 20,000 & & 2000 & 5000 & 10,000 & 15,000 & 20,000 & \\
\hline 1 & $100^{(1)}$ & 100 & 78.3 & 68 & 43.7 & 34.2 & 25.6 & 52.7 & 92.2 & 86.4 & 78.1 & 74.4 & 74.4 & 17.8 \\
\hline 2 & $100^{(1)}$ & 100 & 82.6 & 68.2 & 51 & 41.1 & 34.5 & 48.1 & 91.7 & 82.9 & 74.5 & 69.2 & 65.5 & 26.2 \\
\hline 1 & 300 & 300 & 87.6 & 78.6 & 67.1 & 59.4 & 52.3 & 35.3 & 97.1 & 93.5 & 88.8 & 85.1 & 82.6 & 14.5 \\
\hline 2 & 300 & 250 & 74.5 & 63.9 & 56.6 & 49.3 & 45.2 & 29.3 & 80.8 & 78 & 73.9 & 71 & 68.2 & 12.6 \\
\hline 1 & 600 & 600 & 89 & 83.9 & 75.6 & 69.6 & 63.5 & 25.5 & 98.5 & 96.5 & 93.7 & 91.3 & 89.4 & 9.1 \\
\hline 2 & 600 & 500 & 79.1 & 71 & 63.8 & 59.1 & 50.7 & 28.4 & 82.2 & 80.3 & 78.2 & 75.9 & 74.8 & 7.4 \\
\hline 1 & $n(600) / n(100)$ & & 1.14 & 1.23 & 1.76 & 2.04 & 2.28 & & 1.07 & 1.12 & 1.2 & 1.23 & 1.2 & \\
\hline
\end{tabular}


gave $78.3 \%$ cost coverage to patients $\mathrm{A}-4.3 \%$ less than respondents in the second survey. The difference increased to $8.9 \%$ when $\mathrm{P}_{\mathrm{A}}=\$ 20,000$. Differences are significant at the $1 \%$ level.

In survey 2, the 'start point' was the most dire scenario for patients $\mathrm{A}: \mathrm{P}_{\mathrm{A}}=\$ 20,000$. This may have created a greater willingness to impose costs upon patients $\mathrm{B}$, an embedding effect that may explain the lower share allocated to B when budgets were equal $(n=100)$.

Consistent with the first subsidiary hypothesis-'normal substitution'- the tenfold increase in the price of A led to a reduced cover of between $66 \%$ (survey 1; 100 patients B) and $36 \%$ (survey $2 ; 600$ patients B). Figure $1 \mathrm{a}, \mathrm{b}$ plot the average percentage coverage of $\mathrm{A}$ against its price. To highlight the order effect, results from survey 2 for 100 patients B are also shown in Fig. 1.

Figure 2a, b plot the percentage of the total budget allocated to patients $\mathrm{A}$ as the price rises. The corresponding data are reported in Table 5 along with the opportunity cost, which is imposed upon patients B, measured as the percentage reduction in cost cover per patient. Over the range of observations, the results are inconsistent with the second but consistent with the third subsidiary hypothesis. Increasing price is associated with 'strong sharing'-an increasing, not decreasing, percentage of the budget allocated to A.
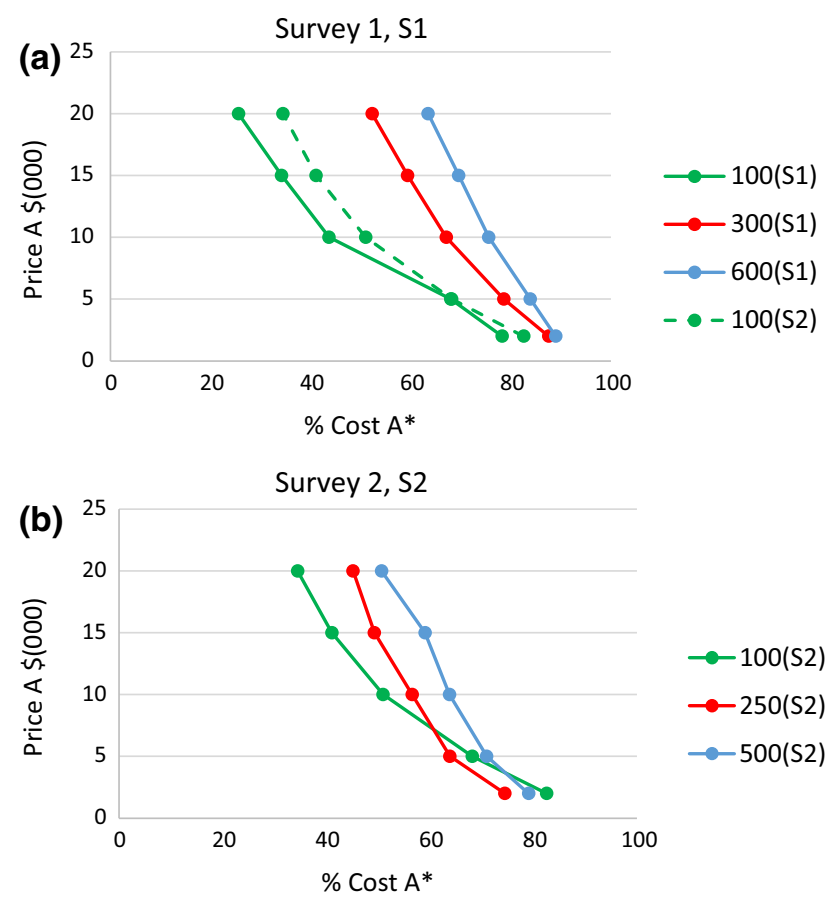

Fig. 1 Percent coverage of total cost of illness A by price A and size of group B. a Survey $1, n=100,300,600$; survey $2 n=100$. b Survey $2, n=100,250,500$. Asterisk Percent of the total cost of A allocated to patients A
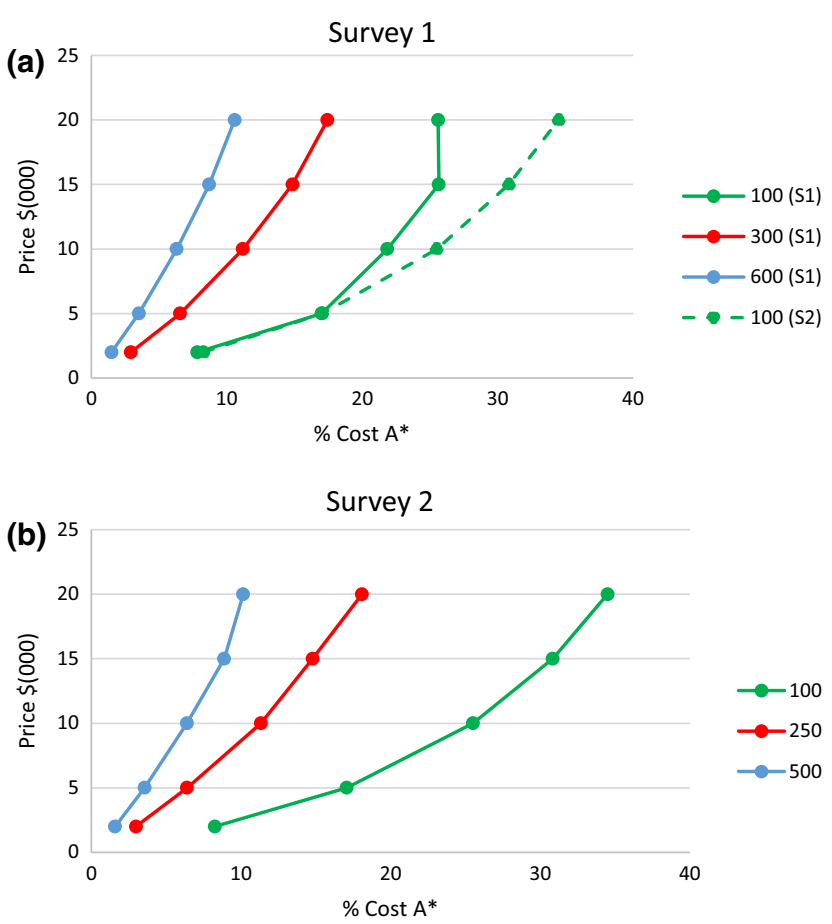

Fig. 2 Percent of budget allocated to patients A as price varies. a Survey 1. b Survey 2. Asterisk Percent of budget A allocated to patients $\mathrm{A}$

Table 6 reports the QALY loss from each scenario. The reduced budget in survey $2(B=300,600)$ is associated with a very significant increase in the net loss, reflecting the greater opportunity cost imposed upon B to maintain sharing in these cases. The same table reports the QALY loss as a percentage of the potential QALYs: the QALYs that would be obtained by following the QALY-maximising strategy of allocating all resources to illness B. As the cost of A rises, QALYs sacrificed to maintain sharing increases.

\subsection{Regression Results}

Table 7 reports the results of regression analyses in which the percent coverage of the cost of $\mathrm{A}$ is the dependent variable. The virtually identical results obtained using OLS and FE techniques implies that the unobserved individual characteristics had no significant effect upon results. Coefficients upon price A and the number of patients B was stable and highly significant regardless of whether or not the total budget was controlled. The coefficient on price A in columns 1-4 implies that across the full dataset an increase in the price from $\$ 2000$ to $\$ 20,000$ reduced cost coverage of $A$ by an average of $36 \%$. The positive sign on the quadratic term suggests that the rising price of $\mathrm{A}$ has a diminishing effect: as the coverage of $\mathrm{A}$ falls there is an increasing unwillingness to reduce it further (columns 
Table 5 Distribution of the budget and the excess burden for $\mathrm{A}^{\mathrm{a}}$

\begin{tabular}{|c|c|c|c|c|c|c|c|c|c|c|c|c|c|c|}
\hline \multirow[t]{3}{*}{ Survey } & \multirow[t]{3}{*}{$\begin{array}{l}\text { Number of } \\
\text { patients B }\end{array}$} & \multirow[t]{3}{*}{$\begin{array}{l}\text { Budget } \\
(\$ 000)\end{array}$} & \multicolumn{5}{|c|}{$\%$ Budget allocated to patients A } & \multirow[t]{3}{*}{$\begin{array}{l}\text { Max- } \\
\text { Min }\end{array}$} & \multicolumn{5}{|c|}{$\begin{array}{l}\text { Opportunity cost per patient B (100- } \\
\% \mathrm{~B})\end{array}$} & \multirow[t]{3}{*}{$\begin{array}{l}\operatorname{Max} / \\
\operatorname{Min}\end{array}$} \\
\hline & & & \multicolumn{5}{|c|}{ Price A } & & \multicolumn{5}{|c|}{ Price A } & \\
\hline & & & 2000 & 5000 & 10,000 & 15,000 & 20,000 & & 2000 & 5000 & 10,000 & 15,000 & 20,000 & \\
\hline 1 & 100 & 100 & 7.8 & 13.6 & 21.9 & 25.6 & 25.6 & 17.8 & 7.8 & 13.6 & 21.9 & 25.6 & 25.6 & 3.28 \\
\hline 2 & 100 & 100 & 8.3 & 17.1 & 25.5 & 30.8 & 34.5 & 26.2 & 8.3 & 17.1 & 25.5 & 30.8 & 34.5 & 4.15 \\
\hline 1 & 300 & 300 & 2.9 & 6.5 & 11.2 & 14.9 & 17.4 & 14.5 & 2.9 & 6.5 & 11.2 & 14.9 & 17.4 & 2.00 \\
\hline 2 & 300 & 250 & 3.0 & 6.4 & 11.3 & 14.8 & 18.1 & 15.1 & 19.2 & 22.0 & 26.1 & 29.0 & 31.8 & 1.66 \\
\hline 1 & 600 & 600 & 1.5 & 3.5 & 6.3 & 8.7 & 10.6 & 9.1 & 1.5 & 3.5 & 6.3 & 8.7 & 10.6 & 7.1 \\
\hline 2 & 600 & 500 & 1.6 & 3.6 & 6.4 & 8.9 & 10.1 & 8.6 & 17.8 & 19.7 & 21.8 & 24.1 & 25.2 & 1.42 \\
\hline
\end{tabular}

${ }^{a}$ In all cases the full price of B was $\$ 1000$. In four of the six cases, the budget is 1000 times the number of patients $\mathrm{B}, n(\mathrm{~B})$. (Survey $1, n=100$, 300,600 ; Survey $2, n=100$ ). In these cases, the opportunity cost per patient $\mathrm{B}$, measured as a percentage reduction in utility, is numerically equal to the percent of the budget allocated to $\mathrm{A}$

Table 6 Net quality-adjusted life-year loss per annum

\begin{tabular}{|c|c|c|c|c|c|c|c|c|c|c|c|c|}
\hline \multirow[t]{3}{*}{ Survey } & \multirow[t]{3}{*}{ Number of patients B } & \multicolumn{5}{|c|}{ QALY Loss } & \multicolumn{6}{|c|}{ Percent possible QALYs lost } \\
\hline & & \multicolumn{5}{|c|}{ Price A } & \multicolumn{6}{|l|}{ Price A } \\
\hline & & 2000 & 5000 & 10,000 & 15,000 & 20,000 & Number of patients B & 2000 & 5000 & 10,000 & 15,000 & 20,000 \\
\hline 1 & 100 & -4.1 & -10.2 & -19.8 & -19.9 & -24.3 & 100 & 4.1 & 10.2 & 19.8 & 19.9 & 24.3 \\
\hline 2 & 100 & -4.2 & -13.7 & -23.0 & -28.7 & -32.7 & 100 & 4.2 & 13.7 & 23.0 & 28.7 & 32.7 \\
\hline 1 & 300 & -4.3 & -15.6 & -30.2 & -41.7 & -49.6 & 300 & 1.4 & 5.2 & 10.1 & 13.9 & 10.9 \\
\hline 2 & 300 & -53.6 & -62.8 & -75.5 & -84.5 & -92.8 & 300 & 21.4 & 25.1 & 30.2 & 33.8 & 37.2 \\
\hline 1 & 600 & -4.6 & -16.8 & -34.0 & -48.7 & -60.4 & 600 & 0.8 & 2.8 & 5.6 & 8.1 & 15.5 \\
\hline 2 & 600 & -104.0 & -114.1 & -128.8 & -141.6 & -148.1 & 600 & 20.8 & 22.8 & 25.8 & 28.3 & 29.6 \\
\hline
\end{tabular}

Table 7 Regression results: dependent variable: percent cover of cost of illness A

\begin{tabular}{|c|c|c|c|c|c|c|}
\hline Independent variables & $\begin{array}{l}\text { (1) } \\
\text { OLS }\end{array}$ & $\begin{array}{l}(2) \\
\text { FE }\end{array}$ & $\begin{array}{l}\text { (3) } \\
\text { OLS }\end{array}$ & $\begin{array}{l}\text { (4) } \\
\text { FE }\end{array}$ & $\begin{array}{l}\text { (5) } \\
\text { OLS }\end{array}$ & $\begin{array}{l}\text { (6) } \\
\text { FE }\end{array}$ \\
\hline Price A & $-2.006[0.056]^{* *}$ & $-2.006[0.056]^{* *}$ & $-2.006[0.056]^{* *}$ & $-2.006[0.056]^{* *}$ & $-3.479[0.162]^{* *}$ & $-3.479[0.162]^{* *}$ \\
\hline Price $A^{2}$ & & & & & $0.067[0.006]^{* *}$ & $0.067[0.006]^{* *}$ \\
\hline No. of patients B & $0.035[0.002]^{* *}$ & $0.035[0.002]^{* *}$ & $0.032[0.002]^{* *}$ & $0.033[0.002]^{* *}$ & $0.032[0.002]^{* *}$ & $0.033[0.002]^{* *}$ \\
\hline Total budget & & & $1.945[0.187]^{* *}$ & $1.771[0.171]^{* *}$ & $1.945[0.187]^{* *}$ & $1.771[0.171]^{* *}$ \\
\hline Age $18-24$ & $4.667[2.544]$ & & $4.769[2.522]$ & & $4.769[2.522]$ & \\
\hline Age $25-34$ & $1.668[2.545]$ & & $1.712[2.535]$ & & $1.712[2.535]$ & \\
\hline Age $35-44$ & $2.259[2.655]$ & & $2.294[2.640]$ & & $2.294[2.640]$ & \\
\hline Age $55-64$ & $1.948[2.840]$ & & $1.886[2.830]$ & & $1.886[2.830]$ & \\
\hline Age $65+$ & $0.469[2.772]$ & & $0.513[2.761]$ & & $0.513[2.761]$ & \\
\hline Male & $-3.259[1.557]^{*}$ & & $-3.217[1.551]^{*}$ & & $-3.217[1.551]^{*}$ & \\
\hline$R^{2}$ & 0.30 & 0.29 & 0.32 & 0.31 & 0.32 & 0.32 \\
\hline Observations & 6480 & 6480 & 6480 & 6480 & 6480 & 6480 \\
\hline
\end{tabular}

$F E$ fixed-effects, $O L S$ ordinary least squares

Cluster robust standard errors reported in brackets

Time-invariant characteristics (age and sex) were excluded from FE estimates. A constant was included in the model $* * p<0.01, * p<0.05$ 
5-6). The coefficient of 0.035 for the number of patients B implies an average increase in coverage of $21 \%$ as the number rises from 100 to 600 . Both results are consistent with tabulated average effects reported in Table 4 . With regard to respondents' demographic characteristics, on average, males allocated significantly less than females to patients A. No significant association was found among different age groups.

\subsection{Rating Questions}

Results from the rating questions reported in the ESM (Appendix 5) are summarised in Fig. 3. There was strong support for the coverage of high-cost illnesses (question 1) and disagreement with their low coverage (question 2). Three considerations were nominated as most important as decisions were being made, namely, the avoidance of terrible health states, fairness in the distribution of health and the amount of total health (questions 5, 6, 9).
Preservation of hope received the second-lowest support (question 8).

\section{Discussion}

Consistent with earlier studies, survey participants divided a fixed budget between high- and low-cost services but, unique to this study, the allocation was shown to be sensitive to the level of sharing and this occurred with full knowledge of the consequences of decisions for total health. Respondents were asked to confirm their understanding of this after each question. A large majority agreed that it is 'OK to reduce services to the majority by a little to cover the cost of very expensive services needed by the few people with rare illnesses' and that 'if services for severe illnesses are very costly, the cost should be shared across the whole community'. The opportunity of creating more health and spreading it among more patients was

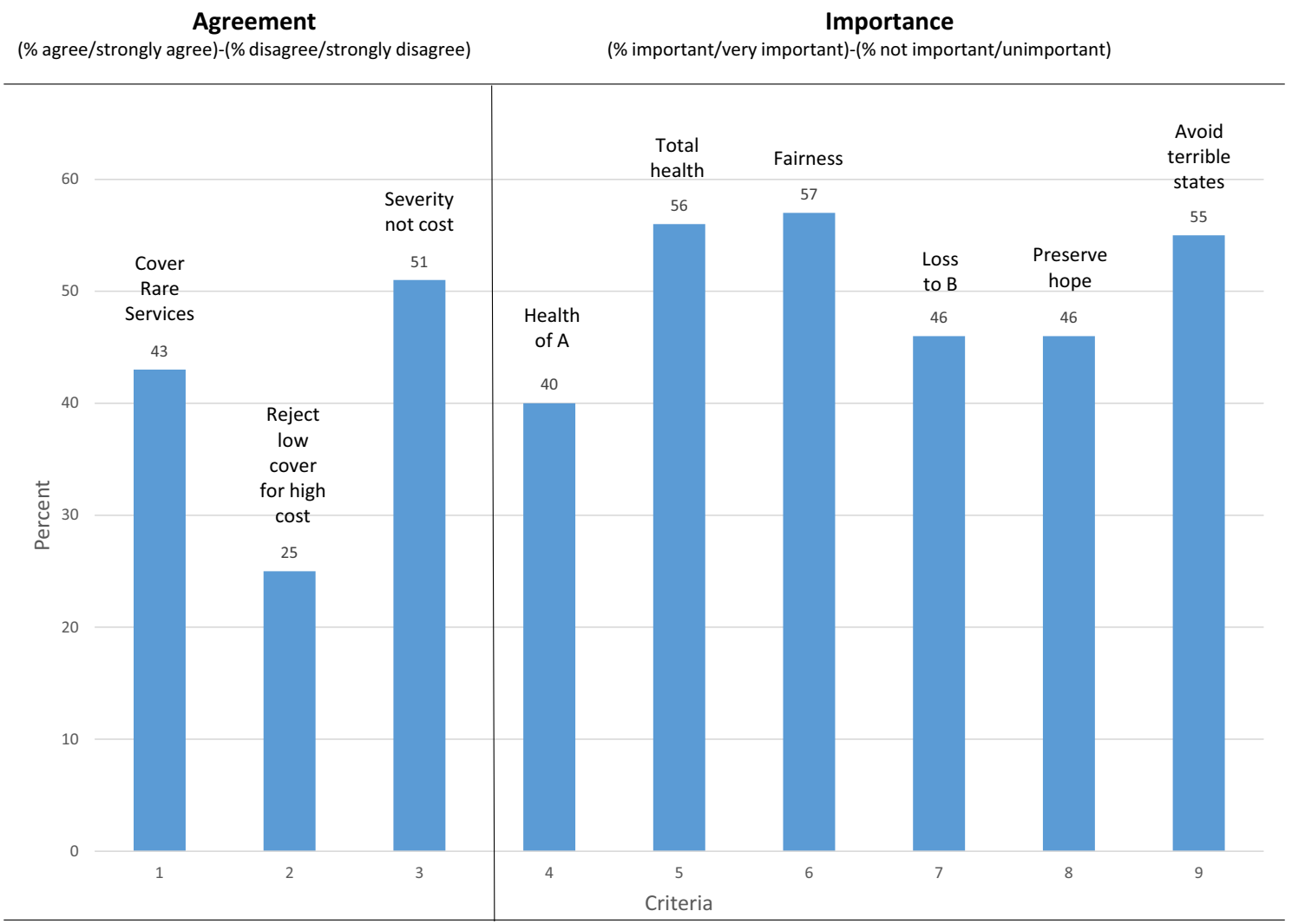

Fig. 3 Net agreement with and importance of allocative criteria. Agreement statements: (1) it is OK to reduce services to the majority by a little to cover the cost of very expensive services needed by the few people with rare diseases. (2) It is (not)* ok to provide the few patients requiring very expensive services with only basic low cost care even if they are left in poor health because Medicare has a limited budget and can't pay for everything. [*'not' inserted here to unify interpretation of Fig. 3]. (3) The severity of illness, rather than the cost of treatment, should determine priority. If services for severe illnesses are very costly the cost should be shared across the whole community. Importance while allocating the budget: (4) The health of patients in Group A. (5) The total amount of health (the area shaded blue). (6) Fairness in the distribution of health. (7) The loss of health in Group B by giving money to Group A. (8) Preserving hope for Group A. (9) Avoiding terrible health states. Source: Electronic Supplementary Material, Tables A.5.1, A5.2 
therefore expressed verbally, visually and as an abstract principle. Therefore, results could not be attributed to a misunderstanding of the opportunity cost.

The effects found in the survey were quantitatively large. The price of A was raised to 20 times the price of $\mathrm{B}$, but this increased sharing to the point where a maximum of $37 \%$ of possible QALYs were foregone to maintain services to the high-cost patients. This was associated with a reduced coverage of the high-cost service, but the reduction depended upon the relative number of patients sharing the cost. From Table 4 the tenfold increase in cost in survey 1 reduced coverage of $\mathrm{A}$ by 52 and 25 percentage points when the numbers of patients B were 20 and 120 times greater than $\mathrm{A}$, respectively.

The striking discrepancy between these results and those cited earlier [15-17, 21, 22] may be attributed to differences in the survey design. In previous surveys, when rarity per se is the focus it is difficult to see reasons for prioritising SRDs above cost-effective services. In contrast, the present study focus was first upon a consequence of rarity, namely the low total cost and therefore the low cost per person affected by funding an SRD. The analogy of a rescue for a sailor lost at sea was used (not to evoke the rule of rescue) to illustrate the moral force of saving someone's life when the cost to any person is only $\$ 5$ because of the sharing of costs. Second, in previous studies the opportunity cost of the treatment of one person with a rare disease was the non-treatment of one or more patients with a common disease. Sharing was not possible because of the experimental design. The main hypothesis of the present study was that, given the opportunity, people have a preference for sharing, albeit with the size of the share varying in the usual way with other relevant variables.

A possible limitation with the present design is that, without the SRD, patient A would die, whereas many SRDs are for non-fatal conditions and results could differ when a patient does not face death. However, the present design permitted respondents to save patient A's life, leave them in a serious health state and allocate the residual budget to the cost-effective service, $\mathrm{B}$; that is, the present design required a choice between the (further) treatment of a nonfatal but severe outcome and the maximisation of health with the residual budget. However, up to $80 \%$ of the cost of A's treatment was covered, implying that sharing does not only occur to save life.

Results are subject to a number of methodological caveats. First, a significant proportion of respondents to web-based surveys provide careless answers. However, from Appendix 4 in the ESM, editing did not alter the main conclusions: their inclusion did not change the effect of price and patient numbers upon sharing. Deleted cases primarily added 'noise'. Second, individuals who enrol with a panel company are self-selected. But there are no evident reasons for believing that people interested in panel surveys would allocate health resources differently from others. Third, despite provision of comprehensive verbal and visual information, questions were cognitively demanding and responses would be affected by participant's use of simplifying heuristics although there was no evidence of the choice aversion found by Dragojlovic et al. [23]. Nevertheless, the significance of framing effects and other potential causes of bias can only be determined by further studies employing alternative methodologies.

Despite the present results, funding SRDs may seem infeasible. In the EU, almost 7000 diseases have been identified that affect fewer than 5 people per 10,000 [32], and their funding may appear to be prohibitively expensive. Challenging this view, at least one projection based upon orphan drug designation in the Eurozone countries concluded that "fears of unsustainable cost escalation do not appear to be justified" [33]. However, such projections reflect an assumed level of coverage of SRDs, and results reported here suggest that this should be greater than at present. But the results do not imply full coverage of all SRDs, and as the average cost imposed on other patients rose, the preferred coverage of SRD patients would fall. This implies that, despite the large number of SRDs, the criteria for obtaining budget support could be revised to expand the scope of sharing without an increase in the total budget. Various criteria for rationing are possible that take account of patient numbers and therefore total cost. One example is given below.

Patient numbers and sharing may be included in the criteria by a simple extension of the present CEA criterion summarised in Eq. 1.

Cost $/ \mathrm{QALY} \leq T$

Cost per QALY must be less than a threshold, $T$, which may be selected to achieve a target budget. The algorithm may be adjusted to Eq. 2 to take account of sharing and severity.

$$
\begin{array}{r}
\text { Cost } / \mathrm{QALY} \leq w T \\
w=f(\operatorname{Sev}, N, \text { Share })
\end{array}
$$

where $w$ is a weight that is a function of the disease severity, $\mathrm{Sev}$ is the number of patients $N$ who have the diseases or the sum of the numbers with a rare disease of equivalent severity and the proportion of the eligible population sharing the cost, 'share'. As severity increases, $w$ will decline: as $N$ increases and the opportunity cost of service provision increases, $\mathrm{w}$ will rise; as sharing increases w will fall. An algorithm satisfying these conditions is illustrated in the ESM (Appendix 3). With universal sharing, this generates values of $\mathrm{w}$, which vary from 0.05 (imminent death affecting $0.001 \%$ of the population) to 2.7 (initial utility, 0.8 , affecting $10 \%$ of the population). The 
data are artefactual but illustrate the possibility of accommodating payment for SRDs subject to a budget cap.

Finally, the results might be seen to imply horizontal inequity between patients who would receive treatment if their illness were rare and costly but not if the illness were common and cheap. However, the survey results do not imply this conclusion as the groups affected were not 'horizontal'. Costs were the result of an incremental reduction from full health, for the larger group, B. The benefit $\mathrm{A}$ was an improvement from death or from very poor health. Results imply less than maximum possible utility. However, population preferences need not conform with consequentialist utilitarianism, which is the only ethical theory that simply aggregates utilities. All other theories take account of the distribution of utilities in a way that reduces their aggregate value. Population preferences may be 'laundered', but the case for this is strongest when preferences are abhorrent or ill informed. The present results are in neither of these categories. They reflect a concern for others; they are consistent with defensible 'communitarian' values and with the significant ethical literature that argues for prioritising the worst-off members of society [34-37].

\section{Conclusions}

A willingness to share is a fundamental characteristic of a communal enterprise. However, at present, the sharing of costs has no part in the theory of economic evaluation. Evidence from the present survey suggests that when patient numbers are small and the average cost to those who share the cost is small, a well-informed public is likely to support the funding or part funding of effective services that are not presently considered 'cost effective' because of their high cost per patient. Constructing an algorithm for allocating the health budget that incorporates these preferences is problematic, but this cannot be taken as evidence that public preferences are unaffected by sharing. In general terms, sharing implies the substitution of a small number of high-cost services for severe health states for a larger number of services for less severe problems. This is an achievable policy.

Acknowledgements Financial support for this study was provided entirely by a grant from the National Health and Medical Research Council (NH\&MRC) project Grant ID 1069241 Measuring healthrelated social preferences and their inclusion in an alternative formula for prioritising health services.

\section{Compliances with Ethical Standards}

Conflict of interest Jeff Richardson, Angelo Iezzi, Gang Chen, and Aimee Maxwell have no conflicts of interest.
Open Access This article is distributed under the terms of the Creative Commons Attribution-NonCommercial 4.0 International License (http://creativecommons.org/licenses/by-nc/4.0/), which permits any noncommercial use, distribution, and reproduction in any medium, provided you give appropriate credit to the original author(s) and the source, provide a link to the Creative Commons license, and indicate if changes were made.

\section{References}

1. Garber AM, Sculpher MJ. Cost effectiveness and payment policy. In: Pauly MV, McGuire TG, Barros PP, editors. Handbook of health economics, vol. 2. Amsterdam: Elsevier North Holland; 2011.

2. Drummond M, Sculpher M, Torrance G, O’Brien B, Stoddart G. Methods for the economic evaluation of health care programs. 3rd ed. Oxford: Oxford University Press; 2005.

3. Nord E. Cost value analysis in health care: making sense out of QALYs. Cambridge: Cambridge University Press; 1999.

4. Dolan P, Shaw R, Tsuchiya A, Williams A. QALY maximisation and people's preferences: a methodological review of the literature. Health Econ. 2005;14(2):197-208.

5. Stafinski T, Menon D, Marshall D, Caulfield T. Societal values in the allocation of healthcare resources: is it all about the health gain? Patient. 2011;4(4):207-25.

6. Whitty JA, Lancsar E, Rixon K, Golenko X, Ratcliffe J. A systematic review of stated preference studies reporting public preferences for healthcare priority setting. Patient. 2014;7:365-86.

7. Gu Y, Lancsar E, Ghijben P, Butler J, Donaldson C. Attributes and weights in health care priority setting: a systematic review of what counts and to what extent. Soc Sci Med. 2015;146:41-52.

8. Schlander M, Adarkwah CC, Gandjour A. budget impact of drugs for ultra-rare non-oncological diseases projected to remain moderate in Europe, discussion paper 30. Wiesbaden: Institute for Innovation and Valuation in Health Care; 2014.

9. Simoens S, Cassiman D, Dooms M, Picavet E. Orphan drugs for rare diseases: Is it time to revisit their special market access status? Drugs. 2012;72(11):1437-43.

10. Drummond M, Wilson DA, Kanavos P, Ubel P, Rovira J. Assessing the economic challenges posted by orphan drugs. Int $\mathbf{J}$ Technol Assess. 2007;23(1):36-42.

11. Drummond M, Towse A. Orphan drugs policies: a suitable case for treatrment. Eur J Health Econ. 2014;15:335-40.

12. Hughes-Wilson W, Palma A, Schuurman A, Simoens S. Paying for the orphan drug system: Break or bend? Is it time for a new evaluation system for payers in Europe to take account of new rare disease treatments? Orphanet J Rare Dis. 2012;7(74). doi:10. 1186/750-72-7-74.

13. McCabe C. Is it time to revisit orphan drug policies? BMJ. 2010;341(c4777). doi:10.1136/bmj.c4777.

14. Schlander M, Garattini S, Holm S, Kolominsky-Rabas P, Nord E, Persson U, et al. Incremental cost per quality-adjusted life year gained? The need for alternative methods to evaluate medical interventions for ultra-rare disorders. J Comp Eff Res. 2014;3(4):399-422.

15. Desser AS. Prioritizing treatment of rare diseases: a survey of preferences of Norwegian doctors. Soc Sci Med. 2013;94:56-62.

16. Desser AS, Gyrd-Hansen D, Olsen JA, Grepperud S, Kristiansen IS. Societal views on orphan drugs: cross sectional survey of Norwegians aged 40-67. BMJ. 2010;341(C4715):1-6.

17. Mentzakis E, Stefanowska P, Hurley J. A discrete choice experiment investigating preferences for funding drugs used to 
treat orphan diseases: an exploratory study. Health Econ Policy Law. 2011;6:405-33.

18. van de Wetering EJ, van Exel A, Rose JM, Hoefman RJ, Brouwer WB. Are some QALYs more equal than others? Eur J Health Econ. 2016;17(2):117-27.

19. McCabe C, Claxton K, Tsuchiya A. Orphan drugs and the NHS: should we value rarity? BMJ. 2005;331:1016.

20. Hughes D, Tunnage B, Yeo S. Drugs for exceptionally rare diseases: do they deserve special status for funding? QJM Int J Med. 2005;98:829-36.

21. Moberly T. Rationing and access to orphan drugs. Pharm J. 2005;275:569-70.

22. Lynley WG, Hughes DA. Societal views on NICE, cancer drugs fund and value-based pricing criteria for prioritising medicines: a cross-sectional survey of 4118 adults in Great Britain. Health Econ. 2013;22(8):948-64.

23. Dragojlovic N, Rizzardo S, Bansback N, Mitton C, Marra CA, Lynd LD. Challenges in measuring the societal values of orphan drugs: Insights from a Canadian stated preference. Patient. 2015;8(1):93-101.

24. Desser AS, Olsen JA, Sverre G. Eliciting preferences for prioritizing treatment of rare diseases: the role of opportunity costs and framing effects. Pharmacoeconomics. 2013;31(11):1051-61.

25. Nord E, Richardson J, Kuhse H, Singer P. Who cares about cost?: does economic analysis impose or reflect social values? Health Policy. 1995;34(2):79-94.

26. Abellan-Perpinan J-M, Pinto-Prades J-L. Health state after treatment: a reason for discrimination? Health Econ. 1999;8:701-7.

27. Ubel P, Loewenstein G. Distributing scarce livers: the moral reasoning of the general public. Soc Sci Med. 1996;42(7):1049-55.

28. Ratcliffe J. Public preferences for the allocation of donor liver grafts for transplantation. Health Econ. 2000;9:137-48.
29. McKie J, Shrimpton B, Richardson J, Hurworth R. The monetary value of a life year: evidence from a qualitative study of treatment costs. Health Econ. 2011;20(8):945-57.

30. Richardson J, Sinha K, Iezzi A, Maxwell A. Maximising health versus sharing: measuring preferences for the allocation of the health budget. Soc Sci Med. 2012;75(8):1351-61.

31. Richardson J, Iezzi A, Maxwell A. Why health insurance should reimburse some cost ineffective services: results from a pilot survey, Research Paper 91. Melbourne: Centre for Health Economics, Monash University; 2015.

32. Schieppati A, Henter JI, Daina E, Aperia A. Why rare diseases are an important medical and social issue. Lancet. 2008;371:2019-41.

33. Schey C, Milanova T, Hutchings A. Estimating the budget impact of orphan medicines in Europe: 2010-2020. Orphanet J Rare Dis. 2011;27(62). doi:10.1186/750-72-6-62.

34. Alkire S, Santos M. A multidimensional approach: poverty measurement and beyond. Soc Indic Res. 2013;112:239-57.

35. Clark DA, Qizilbash M. Core poverty. Vagueness and adaptation: a new methodology and some results for South Africa. J Dev Stud. 2008;44:519-44.

36. Mitchell PM, Roberts TE, Barton PM, Coast J. Assessing sufficient capability: a new approach to economic evaluation. Soc Sci Med. 2015;139:71-9.

37. Rawls J. A theory of justice. Cambridge: Harvard University Press; 1971.

38. ABS. Estimated Resident Population (ERP) by Region, Age \& Sex 2001-2013. Austalian Bureau of Statistics http://www.abs. gov.au/AUSSTATS/abs@.nsf/DetailsPage/3101.0Mar\% 202015?Open. Accessed 23 July 2015. 